\title{
DESIGN AND ANALYSIS OF A TWO STAGE REDUCTION GEARBOX
}

\section{CH. NAVEEN REDDY, M. BHARGAV, V. PRANAY DEEPAK REDDY \&}

\section{T. PRANAY NAG}

Department of Mechanical Engineering, VNR Vignana Jyothi Institute of Engineering and Technology,

Hyderabad, India

\begin{abstract}
An All-Terrain Vehicle is an Off-Road vehicle that has the ability to drive on any terrain without any difficulty. $B A J A$ vehicles are the most famous Off Road Vehicles in India. However, due to the extreme loads caused by the gravel tracks and the constraints to reduce the weight, one major component is susceptible to failure Reduction Gearbox. The Power Train assembly is so complicated that it occupies a lot of space in the vehicle hence increasing the overall weight. The objective of this project is to design a gearbox that is compact, lightweight and has extended life. Major fields covered are Material selection, Machine Engineering Design of Gears, Shafts, Gearbox Casing, bearing selection, Vibrations caused due to the Engine. These analytical designs have been validated through the help of CAD and FEA software like Solid Works and ANSYS. Various Analysis like Structural, repeated loads and Computational Fluid Dynamics (CFD) have been performed to study the behavior of components and oil flow during operations. The design is also finalized with the fits required for assembly and the final product is expected to be efficient, lightweight, compact and long lasting than the other Gearboxes being used today.
\end{abstract}

KEYWORDS: Reduction Gearbox, All-Terrain Vehicle, Finite Element Analysis (FEA) \& Vibrations

Received: May 23, 2018; Accepted: Jun 13, 2018; Published: Jul 16, 2018; Paper Id.: IJMPERDAUG201855

\section{INTRODUCTION}

A reduction gearbox is a device by which an input speed can be lowered for a requirement of slower output speed, with same or more output torque. Reduction gear assembly consists of a set of rotating gears connected to an output shaft. The high-speed incoming motion from the wheel work is transmitted to the set of rotating gears, wherein the motion or torque is changed. The number of gears used in the reduction gear assembly depends on the output speed requirement of the application. The Volvo Group [1] introduced a concept of Automatic Transmissions. It is discussed that Manual Gearboxes are complicated in design and is difficult for the users to drive the vehicle. The power and braking requirements were calculated. On the basis of these requirements and results, a detailed market study was carried out and suitable materials parts and components were selected [2]. John M. Hawkins [5] simplified the design of a gearbox and made it more compact for usages in low power vehicles like Mopeds and Forklifts. Willis, Christopher Ryan [3] (VTechWorks-79677) have developed a CVT design that can be tuned to a range of Reduction ratios. It has been observed that the origin of noises is from the improper meshing of gears in the assembly.

By studying the gearbox theoretically the various parameters related to the gearbox such as types in the gearbox, single stage, multistage gearboxes etc. can be understood. To Design, Analyze the problems being faced in an ATV and overcome all those flaws. Major flaws include weight, size, and cost. Occasional breakdowns and 
constant maintenance have been observed. Design plan includes research and material selection for the Casing, Gears, and shafts. Gear oil selection is also based on market survey and behaviour of fluids at a given temperature range. Once the material is selected, the calculations for minimum dimensions will be calculated. Standard dimensions similar to the minimum dimensions are selected and modeled in CAD software. Various profiles have been created on the components to ensure structural integrity and less weight.

\section{MODELING OF THE COMPONENTS}

After the detailed study of the gearbox, the calculation of the gearbox will be done by considering various parameters. The reduction ratio is decided according to the comfortable engine provided by considering the FMAEBAJA INDIA event. After the reduction ratio was finalized the diameters of the gears, opinions shaft can be fixed and then the selecting the bearing type as well as sizes for the proper functioning of the gearbox. According to the reduction decided we calculated the teeth for the gears and opinions, also calculated the dimensions for shafts and keys. Finally, after all the above calculations, it is decided with the calculations for the casing of the gearbox.

Once the calculations of the gearbox finalized, start the designing of the gearbox virtually on the software such as Solid Works by considering the calculated parameters of the gearbox. The materials selected for various parts as mentioned in table 1 .

Table 1: Materials selected for various parts

\begin{tabular}{|l|l|}
\hline \multicolumn{2}{|c|}{ PARTS LIST } \\
\hline \multicolumn{1}{|c|}{ Part Name } & \multicolumn{1}{c|}{ Material } \\
\hline Spur Gear 1 & 40Ni2Cr1Mo28 (Alloy Steel) \\
\hline Spur Gear 2 & 15Ni2Cr1Mo15 (Alloy Steel) \\
\hline Spur Gear 3 & 40Ni2Cr1Mo28 (Alloy Steel) \\
\hline Spur Gear 4 & 15Ni2Cr1Mo15 (Alloy Steel) \\
\hline Shaft 1 & Plain Carbon Steel (EN8) \\
\hline Shaft 2 & Plain Carbon Steel (EN8) \\
\hline Shaft 3 & Plain Carbon Steel (EN8) \\
\hline Bearing 1 & 100Cr6 Steel \\
\hline Bearing 2 & 100Cr6 Steel \\
\hline Bearing 3 & 100Cr6 Steel \\
\hline Bearing 4 & 100Cr6 Steel \\
\hline Gearbox Casing & Aluminum 7071-T6 \\
\hline M6 Bolt & High Speed Steel(HSS) \\
\hline M6 Nut & High Speed Steel(HSS) \\
\hline
\end{tabular}

The assembling of all components is done using the Assembly module of Solid Works. Rough dimensions of the bearings have also been modeling to ensure perfect assembly. Few interferences have been detected between the gear tooth and the casings but the dimensions have been modified to the casing. After deep inspections of each part, the assembly is not interfering with the components. From the assembly, it is decided that the Gearbox occupies the least space. The final prototype has been shown in figure 1. A rigorous analysis will be conducted on the Assembly. All the components are shown in the exploded view in figure 2. The specifications of the gears and shafts as mentioned in table 2 and 3. 
Table 2: Specifications of the Gears

\begin{tabular}{|l|c|c|c|c|c|c|c|}
\hline \multicolumn{7}{|c|}{ Gear Specifications } \\
\hline Part Name & $\begin{array}{c}\text { PCD } \\
(\mathbf{m m})\end{array}$ & $\begin{array}{c}\text { Addendum } \\
(\mathbf{m m})\end{array}$ & $\begin{array}{c}\text { Deddendum } \\
(\mathbf{m m})\end{array}$ & Teeth & Module & Face Width & Shaft Diameter \\
\hline Gear 1 & 27 & 30.6 & 23.4 & 18 & 1.5 & $15 \mathrm{~mm}$ & $15 \mathrm{~mm}$ \\
\hline Gear 2 & 54 & 57.6 & 50.4 & 36 & 1.5 & $15 \mathrm{~mm}$ & $15 \mathrm{~mm}$ \\
\hline Gear 3 & 33 & 36.6 & 29.4 & 22 & 1.5 & $15 \mathrm{~mm}$ & $30 \mathrm{~mm}$ \\
\hline Gear 4 & 82.5 & 86.1 & 78.9 & 55 & 1.5 & $15 \mathrm{~mm}$ & $30 \mathrm{~mm}$ \\
\hline
\end{tabular}

Table 3: Specifications of Shafts

\begin{tabular}{|l|l|c|c|}
\hline \multicolumn{5}{|c|}{ Shaft Specifications } \\
\hline Part Name & Shaft Type & $\begin{array}{c}\text { Shaft Diameter } \\
(\mathbf{m m})\end{array}$ & $\begin{array}{c}\text { Length } \\
(\mathbf{m m})\end{array}$ \\
\hline Shaft 1 & Constant Diameter & $15 \mathrm{~mm}$ & $76 \mathrm{~mm}$ \\
\hline Shaft 2 & Stepped Shaft & $25 / 30($ Length:38 mm each) & $76 \mathrm{~mm}$ \\
\hline Shaft 3 & Constant Diameter & $30 \mathrm{~mm}$ & $76 \mathrm{~mm}$ \\
\hline
\end{tabular}

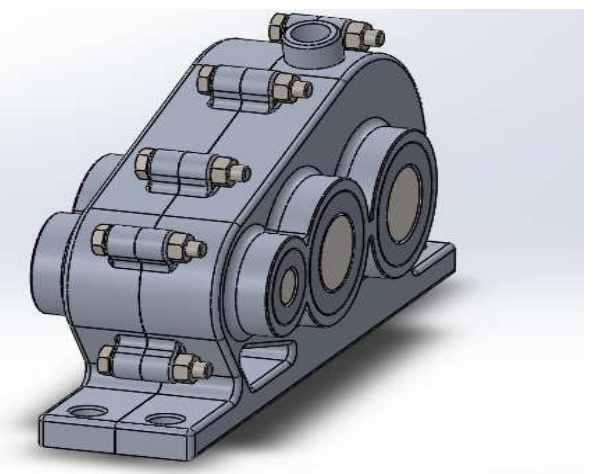

Figure 1: Final Assembly of Gearbox

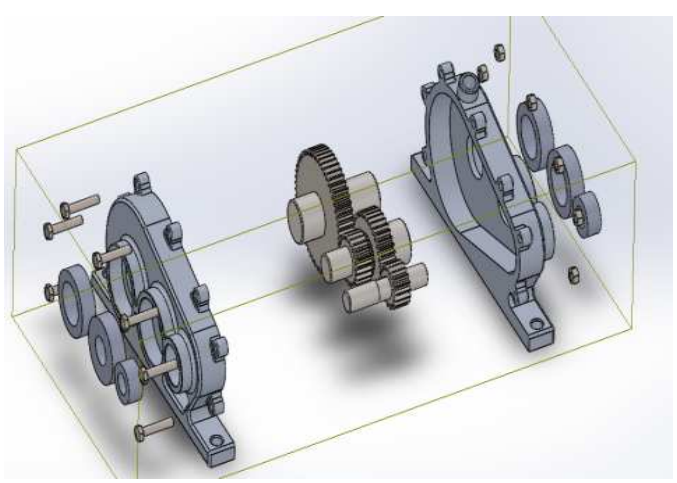

Figure 2: An Exploded View of the Assembly

\section{RESULTS AND DISCUSSIONS}

The results and discussions include static structural analysis on Gears and shafts, vibration and loading effect on the casing, flow analysis using flow simulation.

\section{Forces Acting on the Gears}

The gears inside are subjected to high torque during the operation. Due to the High Torque produced, the gear is subjected to twisting moment from the center of the axis. Since the center of the gear is welded to the shaft, there is negligible resistance offered by the gear against the torque. However, since there is high torque variation from the CVT the 
moment of Inertia of the Gear may resist the torque for a small amount of time (milliseconds). Thought the shaft is attached to Roller bearings that have negligible friction, it is essential to perform torque analysis on the gears assuming that the shaft is fixed rigidly. Different Gears bear different Torques and the loading conditions are applied separately for each Gear. The Loading conditions are mentioned in Table 4.

Table 4: Loading Conditions Applied on Gears

\begin{tabular}{|c|c|c|}
\hline Part Name & Loading Condition & Constrain \\
\hline Gear 1 & 12000 N-mm & Fixed at Shaft Hole \\
\hline Gear 2 & 24000 N-mm & Fixed at Shaft Hole \\
\hline Gear 3 & 16000 N-mm & Fixed at Shaft Hole \\
\hline Gear 4 & 40000 N-mm & Fixed at Shaft Hole \\
\hline
\end{tabular}

The shafts do not fail and have yielded a Factor of Safety between 2.6 to 4 . The deflection is negligible. These gears are safe for the worst operating conditions. Below figure shows that the maximum stress occurs at the base of the gear tooth. Other Results have been mentioned in detail in Table 5 .

Table 5: Loads Acting on Gears

\begin{tabular}{|c|c|c|c|}
\hline Part Name & $\begin{array}{c}\text { Maximum Stress } \\
\text { (MPa) }\end{array}$ & $\begin{array}{c}\text { Maximum Displacement } \\
(\mathbf{m m})\end{array}$ & Factor of Safety \\
\hline Gear 1 & 85.7 & 0.00357 & 2.6 \\
\hline Gear 2 & 69.7 & 0.0038 & 3.2 \\
\hline Gear 3 & 72.7 & 0.00321 & 3.1 \\
\hline Gear 4 & 54.4 & 0.00221 & 4.2 \\
\hline
\end{tabular}

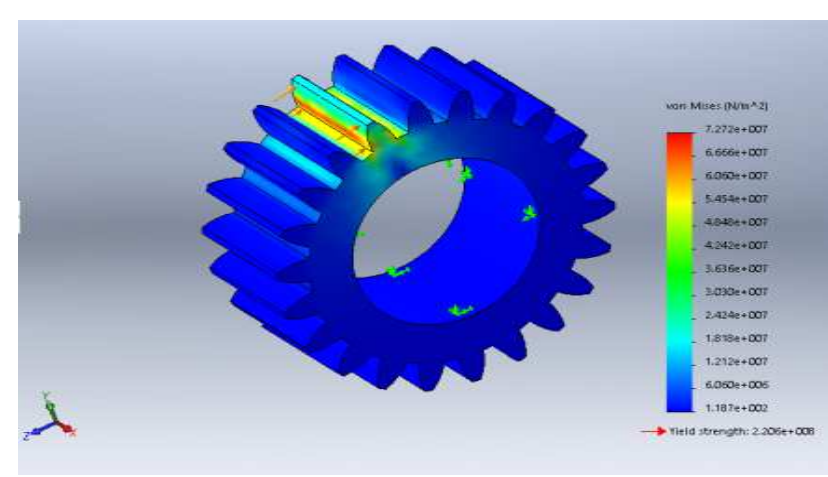

Figure 3: Static Structural Analysis on Gear 3

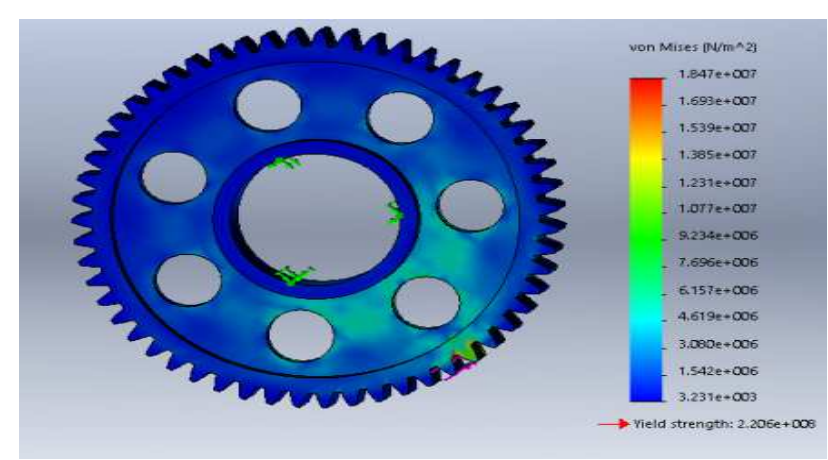

Figure 4: Static Structural Analysis on Gear 4 


\section{Forces Acting on the Shafts}

The gear is welded to the shaft and then Press fitted to the bearings. Only one degree of freedom is not arrested by the assembly - Rotation of shafts. The shafts are made to rate freely on the bearings with the help of the torque transmitted by the gears. There are three major types of forces acting on these shafts, namely-Torsion, Pre -loading of shaft ends due to press fit of bearings and the weight excreted by the Gears. Since the preload force excreted by the bearings cannot be calculated, the main loads focused on are Torsion and the weight of gears. For the intermediate Shaft, there are two Gears mounted on it. Hence, the summations of both the torques generated by the gears are applied. Table 6 shows the loading conditions applied on shafts.

Table 6: Loading Conditions Applied on Shafts

\begin{tabular}{|c|c|c|c|}
\hline Part Name & Torque Applied & Force Applied & Constrain \\
\hline Shaft 1 & $12000 \mathrm{~N}-\mathrm{mm}$ & $1.5 \mathrm{~N}$ & Fixed support at Ends \\
\hline Shaft 2 & $40000 \mathrm{~N}-\mathrm{mm}$ & $3.6 \mathrm{~N}$ & Fixed support at Ends \\
\hline Shaft 3 & $40000 \mathrm{~N}-\mathrm{mm}$ & $2.2 \mathrm{~N}$ & Fixed support at Ends \\
\hline
\end{tabular}

The shafts do not fail and have yielded a Factor of Safety between 2.6 to 3.1. The deflection is negligible. These shafts are safe for the worst operating conditions. Other Results have been mentioned in detail in Table 7. The stresses developed in the shafts as shown in figures $5 \& 6$.

Table 7: Loads Acting on Shafts

\begin{tabular}{|c|c|c|c|}
\hline Part Name & $\begin{array}{c}\text { Maximum Stress } \\
(\mathbf{M P a})\end{array}$ & $\begin{array}{c}\text { Maximum Deflection } \\
(\mathbf{m m})\end{array}$ & Factor of Safety \\
\hline Shaft 1 & 85.7 & 0.00357 & 2.6 \\
\hline Shaft 2 & 69.7 & 0.0038 & 3.2 \\
\hline Shaft 3 & 72.7 & 0.00321 & 3.1 \\
\hline
\end{tabular}

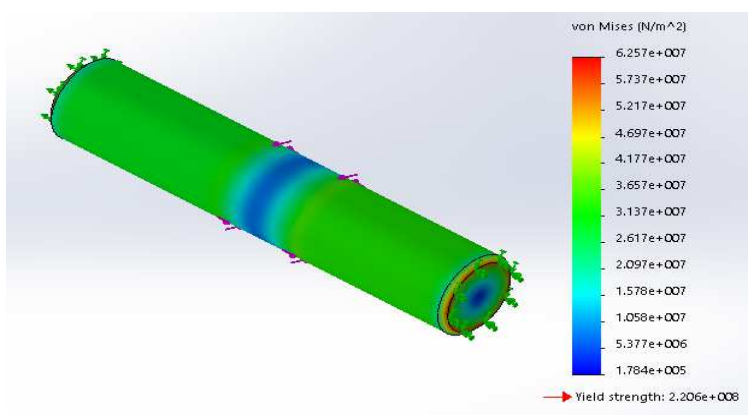

Figure 5: Stress Developed in $1^{\text {st }}$ Shaft

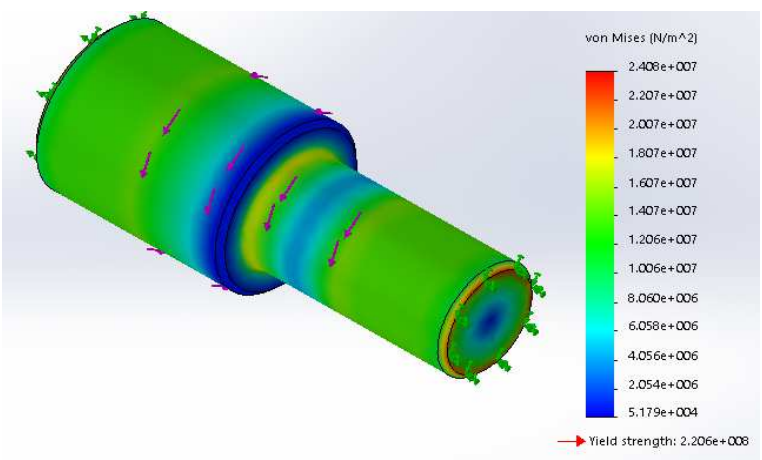

Figure 6: Stress Developed in Intermediate Shaft 


\section{Vibration and Loading Effect on the Casing}

The Vibrations produced by the engine is approximately $50 \mathrm{~Hz}$. The vibrations from the engine are transmitted through the CVT and to the input shaft of the gearbox. Practically, there will be significant loss while transmitting through CVT. For the safety considerations, it is assumed that the CVT can transmit all the Vibration that is produced by the engine. Additionally, the weight of the inside components and the Gear oil is also added to the loading condition. The aim of the analysis is to make sure that the casing absorbs all the vibrations without disturbing the shafts and bearings due to which eccentricity or misalignment takes place. The material of the casing is 7071-T6 Aluminum Alloy that has an Endurance limit of $121 \mathrm{MPa}$. The loading conditions for the Assembly are mentioned in Table 8.

Table 8: Loading Conditions Applied on Assembly

\begin{tabular}{|l|c|c|c|}
\hline Part Name & Torque Applied & Force Applied & Contact/Constrain \\
\hline Shaft 1 & $12000 \mathrm{~N}-\mathrm{mm}$ & $1.5 \mathrm{~N}$ & Frictionless support at Ends \\
\hline Shaft 2 & $40000 \mathrm{~N}-\mathrm{mm}$ & $3.6 \mathrm{~N}$ & Frictionless support at Ends \\
\hline Shaft 3 & $40000 \mathrm{~N}-\mathrm{mm}$ & $2.2 \mathrm{~N}$ & Frictionless support at Ends \\
\hline Gear 1 & $12000 \mathrm{~N}-\mathrm{mm}$ & -- & Bonded contact to the shaft \\
\hline Gear 2 & $24000 \mathrm{~N}-\mathrm{mm}$ & -- & Bonded contact to the shaft \\
\hline Gear 3 & $16000 \mathrm{~N}-\mathrm{mm}$ & -- & Bonded contact to the shaft \\
\hline Gear 4 & $40000 \mathrm{~N}-\mathrm{mm}$ & -- & Bonded contact to the shaft \\
\hline Bolt and Nut & -- & -- & Bonded contact to Casing \\
\hline Casing & $50 \mathrm{~Hz}$ Vibration \& 12 N & Rigid support at Mounts \\
\hline
\end{tabular}

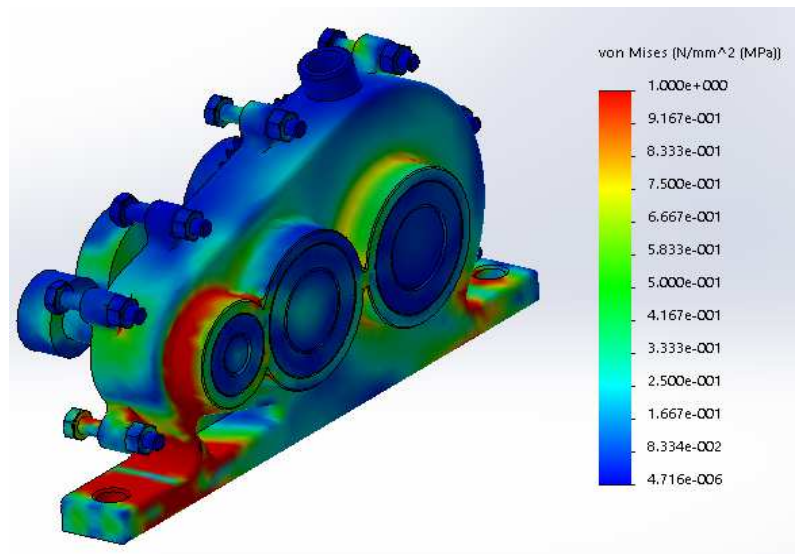

Figure 7: Vibration Analysis on Assembly

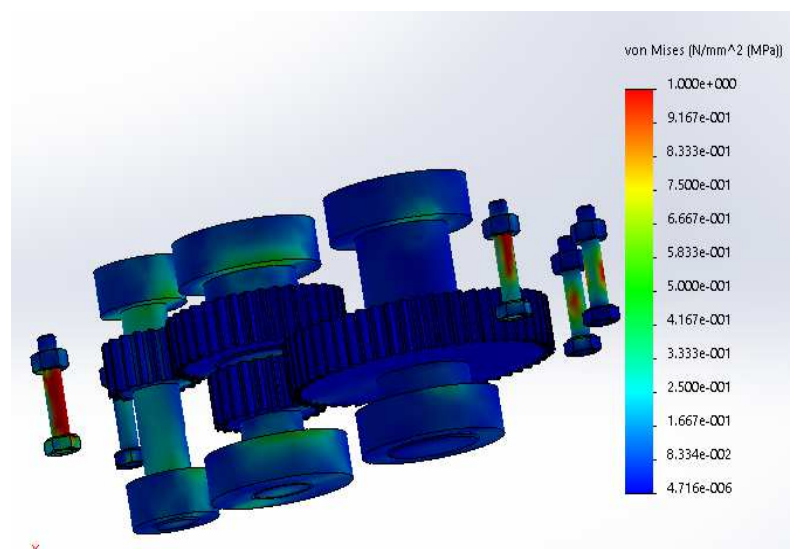

Figure 8: Shafts and Bearings are Majorly Not Affected by Vibrations 


\section{Flow Analysis using Flow Simulation}

It is mandatory to pour oil into the gearbox for essential lubrication and cooling purposes. The amount of oil required is a critical parameter to ensure proper flow. Fill the gearbox completely will result in the inefficient flow of oil to the components. Although lubrication is done, the perfect cooling effect is not achieved. And for the viscosity chose for the gearbox shall be tested so that the oil is reaching to each and every component with ease. In order to understand this phenomenon, Flow simulation has been conducted on the Assembly with the Fluid properties of EP 90. The flow is studied when the Gearbox is at maximum speed. The loading parameters are stated in Table 9.

Table 9: Loading Conditions for CFD

\begin{tabular}{|l|c|}
\hline \multicolumn{1}{|c|}{ Parameter } & Value \\
\hline Working Fluid & EP 90 \\
\hline Kinematic Viscosity & $18 \mathrm{~m}^{2} / \mathrm{s}$ \\
\hline Type of Flow & Laminar and Turbulent \\
\hline Rotating Parts & All Gears, All shafts \\
\hline Rotational Speed & 9000 RPM \\
\hline Fluid Start condition & Stagnant; Gravity \\
\hline Computational Domain & Inside surface of Casing \\
\hline Temperature & Ambient $(300 \mathrm{~K})$ \\
\hline
\end{tabular}

The study of the oil flow is observed in Figure 9. It has been observed that the oil flow is able to cover all the insides of the casing at medium to high speeds. Figure 10 depicts the velocity contours across the rotating components. It is observed that the velocity of oil is maximum at the periphery of the gear showing that the oils are propagating across the gear tooth effectively. At the base of the casing where the oil is accumulated, there is no stagnancy of oil showing that the oil is being continuously recycled throughout. As per the viscosity point of view, the oil is viscous enough to maintain the surface tension when the oil is accumulated between two teeth. That main force that is driving the major part of the oil flow is the intermediate shaft and the stepped gears mounted on it is observed that the maximum velocity of the oil is occurring around the intermediate gears. Therefore, it is concluded that the Intermediate shaft plays an important role in oil propagation and oil flow is efficient in this setup.

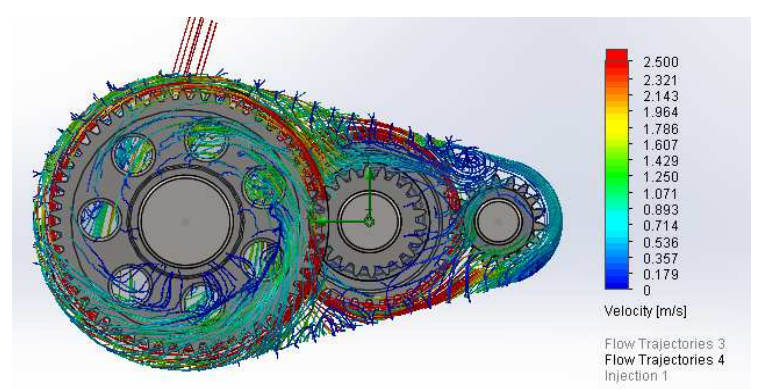

Figure 9: Velocity Contours of Oil Flow 


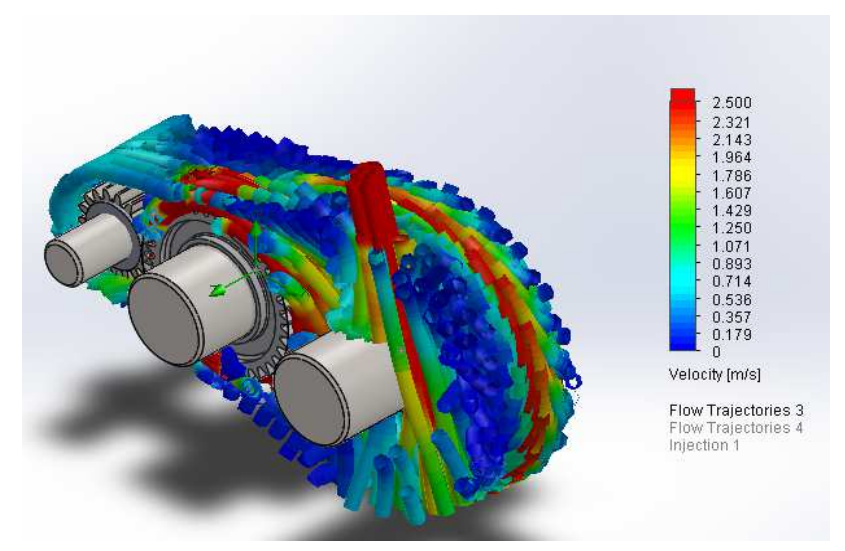

Figure 10: The Oil Flow is Driven by the Movement of Gears

\section{CONCLUSIONS}

Today's Gearboxes in All Terrain Vehicles occupy more space, heavy and have limited life based on the operation. Operating these Gearboxes for continuously will produce heat that may affect the structural integrity. The Reduction Gearbox designed to be coupled with a CVT that can vary the transmission ratios. The transmission ratio of CVT reduces as the Engine RPM increases. Based on the analytical calculations and FEA conclude that all the components are not bound to failure within the given working parameters. The Gearbox is lightweight, compact and has increased life over the conventional Manual Gearboxes.

\section{Final Specifications}

Table 10

\begin{tabular}{|l|l|}
\hline Purpose & $\begin{array}{l}\text { To function as a speed } \\
\text { reducer between CVT and } \\
\text { Differential }\end{array}$ \\
\hline Maximum Dimensions & $180 \mathrm{~mm} * 110 \mathrm{~mm} * 50 \mathrm{~mm}$ \\
\hline Maximum Input RPM & $9000 \mathrm{RPM}$ \\
\hline Maximum Acceleration & $8 \mathrm{~m} / \mathrm{s}^{2}$ \\
\hline Weight & $4.4 \mathrm{Kg}($ Estimated) \\
\hline Total Reduction & 5 \\
\hline Input Shaft Diameter & $15 \mathrm{~mm}$ \\
\hline Output Shaft Diameter & $30 \mathrm{~mm}$ \\
\hline Estimated Cost of Production & $\mathrm{Rs} 18,000 /-$ \\
\hline
\end{tabular}

\section{REFERENCES}

1. Höhn, B-R., and K. Michaelis. "Influence of oil temperature on gear failures." Tribology International 37, no. 2 (2004): 103109.

2. Chetan Wadile, Rohan Dubal, Roshan Kolhe, Versha Rangaswamy, Aqleem Siddiqui \& Nitin Gurav (2013), Selection, Modification and Analysis of Power Transmission and Braking System of an ATV, International Journal on Mechanical Engineering and Robotics (IJMER) Vol.1(1)1, pp.97-102.

3. Aditya Patankar, Rohit Kulkarni, Sanket Kothawade and Sameer Ingle (2016), 'Design And Development of A Transmission System For An All Terrain Vehicle', International Journal of Mechanical Engineering and Technology (IJMET) Vol.7(3), pp.351-359. 
4. Golabi, Sa'id, Javad Jafari Fesharaki, and Maryam Yazdipoor. "Gear train optimization based on minimum volume/weight design." Mechanism and machine theory 73 (2014): 197-217.

5. Nikhil, Y., And TM Jeyashree. "Dynamic Response Of A Cracked Beam Under Free Vibration."

6. Patnaik, Siddhartha. "Design Failure Modes and Effects Analysis (DFMEA) of an all-Terrain Vehicle." International Journal of Research in Engineering and Technology 4.

7. Seshadri, Subhash. "Design and CFD analysis of the intake manifold for the Honda CBR250RR engine." (2015).

8. Patel, Mitesh, A. V. Patil, Mitesh Patel, and A. V. Patil. "Stress and Design Analysis of Triple Reduction Gearbox Casing." International Journal 2: 106-111.

9. Sellgren, Ulf, and M. Akerblom. "A model-based design study of gearbox induced noise." In DS 32: Proceedings of DESIGN 2004, the 8th International Design Conference, Dubrovnik, Croatia. 2004.

10. Teng, Hongzhi, Jianmin Zhao, Xisheng Jia, Yunxian Jia, Xinghui Zhang, and Liying Cai. "Experimental study on gearbox prognosis using total life vibration analysis." In Prognostics and System Health Management Conference (PHM-Shenzhen), 2011, pp. 1-6. IEEE, 2011.

11. Guan, Yuan H., Teik C. Lim, and W. Steve Shepard. "Experimental study on active vibration control of a gearbox system." Journal of Sound and Vibration 282, no. 3-5 (2005): 713-733. 
